\title{
A tradução de regionalismos em A Duel of Farrapos, de João Simões Lopes Neto
}

\section{The translation of regionalisms in João Simões Lopes Neto's A Duel of Farrapos}

\author{
Fernanda Saraiva Frio*
}

Resumo: Este trabalho objetiva analisar as estratégias empregadas na tradução do conto Duelo de Farrapos, do escritor João Simões Lopes Neto. A obra desse escritor é marcada por um dialeto pampeano, repleta de regionalismos e platinismos, resultado do contato direto com os países vizinhos Uruguai e Argentina. Neste artigo, busca-se observar como se deu a tradução das categorias culturais (AIXELÁ, 1996) presentes no texto, isto é, dos itens que possuem uma conotação particular acessível somente a uma determinada comunidade linguística. A tradução do conto foi realizada pelas tradutoras Rosalia Neumann Garcia e Carolina Kuhn Facchin, ligadas ao curso de Tradução da Universidade Federal do Rio Grande do Sul (UFRGS). A análise dos dados mostra que houve um esforço em manter as referências culturais, ora substituindo-as por referências mais gerais, ora utilizando referentes culturais semelhantes.

Palavras-chave: Estratégias de tradução; Regionalismo; Simões Lopes Neto.

Abstract: This work aims to analyze the strategies employed in the translation of the short story A Duel of Farrapos, by João Simões Lopes Neto. His work is marked by a pampean dialect, full of regionalism and Spanish words, as a result of direct contact with the neighboring countries of Uruguay and Argentina. In this article, we seek to observe how the culture-specific items (AIXELÁ, 1996) - that is, items that have a particular connotation accessible only to a particular linguistic community - were translated. The translation of the short story was carried out by the translators Rosalia Neumann Garcia and Carolina Kuhn Facchin, linked to the Translation Program of Universidade Federal do Rio Grande do Sul (UFRGS). The data analysis shows that there was an effort to preserve cultural references, sometimes replacing them with generic terms, sometimes using similar cultural references.

Keywords: Translation Strategies; Regionalism; Simões Lopes Neto.

\footnotetext{
* Doutoranda do Programa de Pós-graduação em Estudos da Tradução da Universidade Federal de Santa Catarina (PGET-UFSC). Sua pesquisa concentra-se na área de Estudos Sistêmico-Funcionais da Tradução e Tradução Teatral. E-mail: fernandasfrio@gmail.com
} 


\section{Introdução}

Este trabalho busca analisar a tradução do conto Duelo de Farrapos, do escritor gaúcho João Simões Lopes Neto, e, mais precisamente, observar como foram vertidos os regionalismos presentes no texto, traço constante e distintivo na obra do autor. Resultado de um esforço conjunto de professores e alunos da Universidade Federal do Rio Grande do Sul (UFRGS), e contando com a colaboração da Universidade Federal de Minas Gerais (UFMG) e da Universidade de São Paulo (USP), além de instituições internacionais, foi lançada, em 2017, a obra Simões Lopes Neto para o Mundo, que reúne a tradução de dez de seus contos para dez idiomas diferentes. A Duel of Farrapos, como ficou o nome do conto em inglês, foi traduzido por Rosalia Neumman Garcia, professora associada da UFRGS, e Carolina Kuhn Fachin, tradutora e revisora, bacharel em Letras pela mesma instituição.

Simões Lopes Neto nasceu na cidade de Pelotas, no Rio Grande do Sul, em 1865, e, apesar de ter falecido aos 51 anos, em 1916, vivenciou profundas mudanças em sua terra natal e no mundo todo, como o fim da Primeira Grande Guerra, a Abolição da Escravatura, a Proclamação da República e a modernização das cidades (FISCHER, GARCIA, LUCENA 2017). Oriundo de uma família nobre, tendo estudado nas melhores escolas e desenvolvido projetos ligados à educação e à literatura, o escritor pelotense obteve pouco reconhecimento em vida, deixando como principal legado os livros Contos Gauchescos, lançado em 1912, e Lendas do Sul, publicado no ano seguinte. Em sua obra, buscou retratar a vida do homem campeiro do pampa sul-riograndense, figura que vinha sendo gradativamente apagada conforme $O$ mundo como um todo ia se modernizando (FISCHER, GARCIA, LUCENA 2017; SCHLEE 2010).

Uma das caraterísticas mais marcantes do texto simoneano é a presença de uma linguagem permeada de regionalismos, platinismos, algumas palavras já em desuso, dentre outros, o que faz com que seu trabalho seja dotado de um linguajar campeiro, característico do gaúcho do pampa, região meridional da América do Sul que compreende parte do Rio Grande do Sul, da 
Argentina e do Uruguai. Por estar inserido neste entre-lugar, a singularidade linguística de JSLN conta com o substrato tanto da língua portuguesa quanto da língua espanhola, criando um dialeto que, de acordo com Schlee (2010, p. 88), é, acima de gauchesco, literário:

Em vez de se valer da língua literária, deformando-a preconceituosamente para produzir uma artificialidade, como fizeram seus contemporâneos e antecessores, chamados de regionalistas, JSLN partiu da própria fala do gaúcho, recompondo-a, aprimorando-a e adequando-a às necessidades expressivas de sua literatura.

Assim, a escrita do autor é representativa da fala do homem campeiro, e busca resgatar as histórias daqueles de origem mais humilde, através de acontecimentos verídicos e de lendas da região pampiana, em uma poética que busca diminuir a distância entre língua escrita e oralidade, sem, no entanto, escrever de forma artificial ou caricata.

Duelo de Farrapos é uma crônica histórica que narra a luta entre personagens reais, os coronéis Bento Gonçalves e Onofre Pires, líderes da Revolução Farroupilha. 0 narrador-personagem Blau Nunes observa o embate entre ambos, mas nada pode fazer, e inclui em sua narrativa uma personagem feminina, descrita como bela e perspicaz, que é quem supostamente causa a rixa entre essas figuras históricas.

Neste artigo, será analisada a tradução do conto Duelo de Farrapos, de modo a descrever as soluções empregadas pelas tradutoras quando deparadas com o vocabulário singular e repleto de referências culturais de JSLN. Na seção seguinte, será delineado o referencial teórico, esclarecendo conceitoschave para este trabalho e trazendo as reflexões de autores que apresentaram tipologias para estratégias de tradução que podem ser empregadas nas mais diversas situações tradutórias - especialmente em casos tão desafiadores como o é a obra do escritor gaúcho. Em seguida, serão descritos os métodos empregados no cotejo dos textos e na seleção dos vocábulos e expressões analisados. Posteriormente, serão apresentados e discutidos exemplos da tradução dos regionalismos presentes no conto. Por fim, serão traçadas as considerações finais deste artigo. 


\section{Referencial teórico}

Antes de se efetuar qualquer análise, é preciso esclarecer os conceitos que informam o estudo. Como se trata de um trabalho sobre a tradução de regionalismos, esta será a primeira definição apresentada aqui, seguida das noções de "estratégias de tradução" e "referências/itens culturais", essenciais para que a escolha dos vocábulos e expressões analisados não incorressem na seleção de palavras que soam regionalistas mas são meramente arcaísmos.

A noção de regionalismo é entendida, aqui, como aquilo que distingue o "eu" do "outro", isto é, como parte do dialeto formadora de uma identidade regional, conforme explica Pozenato (2003, p. 59):

O regionalismo pode ser identificado como uma espécie particular de relações de regionalidade: aquelas em que o objetivo é o de criar um espaço - simbólico, bem-entendido - com base no critério da exclusão, ou, pelo menos, da exclusividade. Esse critério se manifesta, no caso da produção literária, pelo uso de um dialeto, quando não de uma língua, de estrita circulação interna.

Dessa forma, o regionalismo abarca tudo aquilo que é parte restrita da cultura sul-rio-grandense e, mais precisamente, da cultura pampiana. 0 dialeto regional se manifesta não apenas através de vocábulos específicos que se referem à cultura gaúcha, mas também por meio de expressões e interjeições de acento pampeiro e platino - como “Chê!” ou "Barbaridade!". Aqui, é importante ressaltar que, conforme nos lembra Faé (2011), ainda que se utilize de linguajar típico do Rio Grande do Sul, a obra de JSLN não tenciona ser acessível somente a essa região, e sim trata de temas que são universais.

Quanto às estratégias de tradução - também chamadas de métodos, procedimentos etc. - que serão exploradas na seção de análise, de acordo com Chesterman (2016) ${ }^{1}$, trata-se de meios que os tradutores encontram para

\footnotetext{
${ }^{1}$ A obra foi publicada originalmente em 1997, mas ganhou nova edição no ano de 2016.
} 
conformar-se com as normas de seu projeto de tradução, isto é, levando em conta os preceitos da língua de chegada, a delimitação de seu público receptor e a distância cultural entre as duas línguas envolvidas.

0 tradutor deve encontrar meios de lidar com os problemas que surgem ao longo do processo, de modo que o resultado final seja uma tradução considerada adequada para os preceitos da cultura de chegada.

Aixelá (1996), em um texto dedicado especificamente às estratégias tradutórias de elementos culturais, indica outros aspectos que devem ser levados em conta na hora de determinar qual procedimento tradutório deve ser empregado, como o grau de prescritivismo linguístico do texto de chegada, os objetivos dos responsáveis pela publicação da tradução, as condições de trabalho, formação e status social do tradutor.

Também deve se ter em conta os parâmetros textuais, como o tipo de texto, a existência de traduções anteriores do mesmo autor, gênero ou texto e o grau de canonização da obra a ser traduzida.

0 autor aborda o conceito de culture-specific items - que chamaremos, doravante, de categorias culturais -, que ele define como itens que causam um problema à tradução por não existirem ou por terem status diferente na cultura de chegada:

Uma categoria cultural não existe sozinha, mas como resultado de um conflito que surge de qualquer referência representada linguisticamente em um texto de partida que, quando transferida para uma língua de chegada, cria um problema de tradução devido à não existência ou ao valor diferente (seja determinado por ideologia, uso, frequência etc.) desse item na cultura da língua de chegada $^{2}$ (AIXELÁ, 1996, p. 57, tradução minha).

Categorias culturais, portanto, são todos aqueles elementos que não encontram correspondência na cultura de chegada, ou que, ainda que tenham um correspondente, este não tem o mesmo valor nos dois contextos culturais.

\footnotetext{
${ }^{2}$ A CSI does not exist of itself, but as the result of a conflict arising from any linguistically represented reference in a source text which, when transferred to a target language, poses a translation problem due to the nonexistence or to the different value (whether determined by ideology, usage, frequency, etc.) of the given item in the target language culture.
} 
Outro trabalho que se dedica a elencar estratégias para a tradução de itens culturais é o de Newmark (1988), que toma por base as conceituações de Eugene Nida. $\mathrm{O}$ autor entende como cultura tudo aquilo que é peculiar a determinada comunidade linguística. Ele divide as categorias culturais em quatro grupos, quais sejam: (1) ecologia; (2) cultura material; (3) cultura social; (4) organizações, costumes, atividades; (5) hábitos. A ecologia está relacionada à fauna, flora e ao clima, categorias geralmente destituídas de valor político e comercial. A cultura material tem a ver com artefatos como meios de transporte, roupas e comida, sendo esta, para o autor, o elemento mais importante na representação de uma cultura. A cultura social, por sua vez, está ligada ao trabalho e ao lazer, como a prática de esportes e outras atividades. 0 quarto item compreende o cenário político, religioso e artístico, podendo causar problemas para o tradutor quando ele depara com documentos oficiais, por exemplo. Finalmente, os gestos e hábitos compreendem manifestações culturais presentes em todas as esferas do cotidiano, e podem exigir adaptação quando transportados para um novo contexto cultural.

Por fim, em sua obra de 1992, revisitada em 2018, Baker trata de dificuldades na tradução, que podem surgir tanto no nível da palavra quanto em níveis mais complexos, como o pragmático e o semiótico. Por questões de espaço, não serão exploradas em detalhe todas as estratégias sugeridas por esses autores, mas sim aquelas que podem ser observadas na prática e que foram usadas pelas tradutoras para verter Duelo de Farrapos.

Chesterman (2016) divide as estratégias tradutórias em 3 grandes grupos: estratégias de natureza (1) sintática, (2) semântica e (3) pragmática. Somente no domínio da pragmática o autor sugere um procedimento para lidar com categorias culturais, a que ele chama cultural filtering, que pode consistir ou em adaptar o termo para se adequar à cultura de chegada, ou em conservá-lo para provocar estranhamento no leitor.

Aixelá (1996) também divide seus procedimentos em 2 grandes grupos, quais sejam conservação, quando se preserva a categoria cultural sem alterála ou pouco a alterando, ou substituição, quando há algum grau de adaptação da categoria cultural. Dentre os métodos de conservação, estão a repetição 
do item, sua tradução linguística e a inclusão de uma glosa, seja ela no corpo do texto ou fora dele, na forma de uma nota de rodapé, por exemplo. Quanto à substituição, ela pode ocorrer através do uso de sinonímia, de uma categoria cultural mais genérica ou de um referente totalmente neutro, da naturalização do termo para a cultura de chegada, da omissão do termo ou de sua troca por um referente que não existia no texto de partida.

Newmark (1988) apresenta uma tipologia bastante semelhante, mas traz algumas reflexões diferentes. 0 autor traça uma distinção entre o que chama de equivalente cultural e equivalente funcional (cultural equivalent e functional equivalent), respectivamente, o uso de um referente cuja carga cultural seja aproximada da palavra ou expressão presente no texto de partida e o uso de uma palavra sem carga cultural, quando não há equivalência entre os dois contextos culturais.

Outras três estratégias não abarcadas na obra de Aixelá (1996) são o que Newmark (1988) chama de transposição, de modulação e de compensação. A transposição consiste em fazer alterações no domínio gramatical (mudanças de número, grau, tempo/modo verbal etc.), modulação compreende mudanças de perspectiva, refletindo a maneira como cada língua interpreta sua realidade cultural e, por fim, a compensação é utilizada para reparar perdas de significado que ocorrem em determinada parte do texto, recorrendo a uma referência cultural em outra.

Baker (2018) prevê uma série de problemas que podem surgir ao longo da atividade tradutória, e posteriormente apresenta possíveis soluções para eles. Dentre os percalços que o tradutor pode encontrar, a autora cita conceitos específicos de uma cultura, a não-lexicalização desses conceitos, a carga semântica complexa e/ou diversificada das categorias culturais, a falta de hiperônimos ou hipônimos na língua de chegada que deem conta de tentar abarcar o significado mais geral do conceito, as diferentes frequências de uso, a possibilidade de a própria categoria cultural ser um empréstimo de outra cultura, dentre outros. A autora também lista uma série de estratégias para lidar com esses problemas, já abarcadas nas tipologias de Aixelá (1996) e Newmark (1988). 
Para melhor ilustrar os conceitos trabalhados até aqui, o Quadro 1 traz algumas das estratégias mencionadas, com o nome dado pelos autores e sua descrição; optou-se por elencar somente os procedimentos que serão abordados na sessão de discussão dos resultados deste artigo.

\begin{tabular}{|c|c|c|c|}
\hline Aixelá (1996) & Newmark (1988) & Baker (2018) & Descrição \\
\hline Universalização & $\begin{array}{l}\text { Equivalente } \\
\text { funcional }\end{array}$ & $\begin{array}{l}\text { Tradução por uma } \\
\text { palavra mais } \\
\text { neutra/menos } \\
\text { expressiva }\end{array}$ & $\begin{array}{l}\text { Substituição da } \\
\text { categoria cultural } \\
\text { por uma referência } \\
\text { mais genérica. }\end{array}$ \\
\hline Repetição & Transferência & $\begin{array}{l}\text { Tradução através } \\
\text { de um empréstimo }\end{array}$ & $\begin{array}{l}\text { Preservação da } \\
\text { referência original. }\end{array}$ \\
\hline Naturalização & Naturalização & & $\begin{array}{l}\text { Adaptação } \text { da } \\
\text { morfologia e da } \\
\text { fonética da palavra } \\
\text { à língua de } \\
\text { chegada. }\end{array}$ \\
\hline & $\begin{array}{l}\text { Equivalente } \\
\text { cultural }\end{array}$ & $\begin{array}{l}\text { Tradução } \\
\text { substituição } \\
\text { cultural }\end{array}$ & $\begin{array}{l}\text { Uso de uma } \\
\text { categoria cultural } \\
\text { cujo significado } \\
\text { não seja o mesmo, } \\
\text { mas que tenha } \\
\text { impacto similar no } \\
\text { leitor. }\end{array}$ \\
\hline
\end{tabular}

Quadro 1 - Tipologia de estratégias de tradução

O Quadro 1 mostra que, apesar de alguns conceitos coincidirem, nem todos são explorados por todos os autores, daí a importância de se recorrer a obras diversas e verificar como cada pesquisador contribui para o debate sobre estratégias de tradução. Na seção a seguir é descrito brevemente o método utilizado para selecionar as categorias culturais dotadas de regionalismo.

\section{Método}

Em primeiro lugar, foi realizada uma revisão da literatura, dos textos que discorrem sobre estratégias de tradução, dando especial atenção àquelas 
que tratam de problemas de natureza cultural, até aquelas que tratam da prosa de JSLN, seu dialeto literário e o uso de regionalismos em seu texto. Em seguida, foi feita uma leitura do conto Duelo de Farrapos, do livro Simões Lopes Neto para o Mundo (FISCHER, GARCIA, LUCENA 2017), quando foram pré-selecionados os vocábulos que poderiam fazer parte da análise. A seleção se baseou, primeiramente, na curadoria das próprias tradutoras, que sinalizavam palavras que poderiam ser obscuras para o leitor em geral com notas de rodapé. Alguns vocábulos que não estavam sinalizados também foram selecionados, uma vez que poderiam se tratar de regionalismos, mesmo sendo de conhecimento do público em geral.

Para determinar se as palavras e expressões pré-selecionadas eram de fato próprias da região pampeira/gaúcha, foram consultados dicionários de Língua Portuguesa e o Vocabulário de João Simões Lopes Neto (SCHLEE 2009), de modo a eliminar todos aqueles termos que não pudessem ser considerados regionalismos.

Depois disso, o texto em português foi cotejado com $A$ Duel of Farrapos, para observar a tradução dos termos selecionados. Os vocábulos em português e em inglês foram dispostos em uma tabela, acompanhados de seus respectivos significados e da anotação da(s) estratégia(s) de tradução empregada(s) em sua tradução. Na seção a seguir, serão trazidos alguns exemplos para demonstrar, na prática, o emprego dos procedimentos de tradução no trato dessas categorias culturais do texto simoneano.

\section{Discussão}

Nesta seção, será utilizada a terminologia de estratégias de tradução proposta por Newmark (1988), quais sejam (1) equivalência funcional, (2) transferência, (3) naturalização e (4) equivalência cultural. É importante ressaltar que, por mais que se esteja usando a tipologia adotada por este autor, as descrições dos procedimentos de tradução e dos exemplos tomam por base as obras de Newmark (1988), Aixelá (1996) e Baker (2018). 


\subsection{Ocorrências de equivalência funcional}

A equivalência funcional, conforme Newmark (1988), ocorre quando, não havendo correspondente para a categoria cultural no texto de chegada, é empregada uma referência mais genérica, como pode ser verificado no exemplo a seguir:

(TP) Agora veja vancê se não foi mesmo o fungu daquela tal dona emissária dum dos dois sorros castelhanos - que veio transtornar tanta amizade dos farrapos?...

(TC) Now you tell me if it wasn't some hocus pocus from that lady the messenger of one of the Uruguayan foxes - that got in the way of the deep friendship between the Farrapos?...

No exemplo acima, a palavra castelhano, que denota pessoas nascidas no Uruguai ou na Argentina, sofre uma redução em seu significado, no entanto, como não há equivalente em inglês para este vocábulo, as tradutoras tiveram de fazer uma escolha, para que não fosse necessário inserir no texto uma glosa longa e que pudesse perturbar a leitura.

A equivalência funcional também pode ocorrer quando, não havendo equivalente na cultura de chegada, é usado um termo genérico e neutro (NEWMARK, 1988), como no exemplo a seguir:

(TP) Ah! esqueci de dizer a vancê que, atravessada debaixo da sobrecincha de cada flete, vinha uma espada.

(TC) Oh! I forgot to tell you that under the cinch 'round each horse, there was a sword.

A palavra flete é usada para designar os cavalos de excelentes condições e qualidades, que são tratados de forma luxuosa. No texto de chegada, foi usado o hiperônimo cavalo, evitando que haja glosas no texto ou uma explicitação do vocábulo na tradução. 
O exemplo abaixo traz outra palavra com uma carga cultural e regionalista, que foi substituída por uma referência mais genérica:

(TP) Rivera era mais valente; Oribe era mais sorro; mas, os dois, matreiraços!...

(TC) Rivera was the braver of the two; Oribe, the smarter: but both, sly as a fox!...

A palavra sorro é sinônimo de "esperto", e ganhou essa conotação porque "sorro" é o nome de um mamífero semelhante à raposa, também chamado de "graxaim". No excerto acima do TC, foi usado um vocábulo mais genérico para traduzi-la.

\subsection{Ocorrências de equivalência cultural}

A equivalência cultural, de acordo com Newmark (1988), é empregada quando se usa referência cultural aproximada daquela presente no texto de partida, como pode ser observado no exemplo:

(TP) Não sei por que chichos pleitos o general e o coronel Onofre Pires tiveram um desaguisado.

(TC) I don't know what fly speck got to the general and Colonel Onofre Pires, but they quarreled.

A expressão chichos pleitos é um platinismo que faz referências a questões de menor importância, pouco relevantes. Já fly speck tem conotação bastante semelhante, de coisas pequenas, insignificantes.

Outro exemplo de equivalência cultural aparece no exemplo a seguir:

(TP) E quando parei e os dois vultos se chegaram, conheci que eram o meu general e o coronel Onofre. E desarmados, chê!... 
(TC) And when I stopped and both figures came closer, I recognized my general and my colonel Onofre. And unarmed, by ginger!...

A interjeição chê! - também grafada como tchê! - é um vocativo amplamente usado no Rio Grande do Sul, e serve para interpelar um interlocutor ou para expressar espanto. Já expressão by ginger! é definida como "uma exclamação eufemística antiquada" (HENDRICKSON 2000), um regionalismo norte-americano.

A seguir, pode ser analisado mais um exemplo de categorias culturais aproximadas:

(TP) 0 [cavalo] colorado era do coronel; o picaço, do general.

(TC) The chestnut was the colonel's; the black, the general's.

A designação colorado faz referência a qualquer coisa cuja cor seja vermelha, nesse caso, está sendo usada para descrever um cavalo de pelo predominantemente avermelhado. No texto de chegada, as tradutoras optam por descrever o pelo do animal como chestnut, isto é, um vermelho mais escurecido, próximo do marrom, uma cor parecida com a da castanha-daíndia.

\subsection{Ocorrências de naturalização}

A naturalização ocorre quando uma palavra do texto de partida é reescrita no texto de chegada, sendo adaptada morfologicamente e foneticamente à língua para a qual se está traduzindo (NEWMARK 1988; AIXELÁ 1996). Algumas dessas naturalizações já existem em dicionários de língua inglesa, como se pode ver no próximo exemplo:

(TP) Se era linda a beldade!... Sim, senhor, dum gaúcho de gosto alçar na garupa e depois jurar que era Deus na terra!... (TC) And was she ever a looker, that beauty!... Yes, sir, the type a 
proud gaucho positively snatch up on his saddle and then swear he was God on Earth!

A palavra gaúcho, na cultura do Rio Grande do Sul, tem uma carga cultural bastante ampla, referindo-se ao campeiro pampeano que habitava as pastagens sul-rio-platenses e sul-rio-grandenses. Ela já está dicionarizada em obras de referência de língua inglesa, mas com uma descrição mais genérica, de homem do pampa Sul-Americano. Esta foi a única ocorrência de naturalização encontrada na tradução do Duelo de Farrapos.

\subsection{Ocorrências de transferência}

A transferência ocorre quando o tradutor opta por manter a categoria cultural intacta, tomando-a como empréstimo e inserindo-a na língua de chegada (NeWMARK 1988; AIXELÁ 1996). O exemplo abaixo mostra uma palavra que já era empréstimo no próprio texto de partida, apesar de já ter sido naturalizada e estabelecida no dialeto gaúcho, e que foi assim preservada no texto de chegada:

(TP) Maneei os mancarrões e com um olho no padre, outro na missa, por entre as ramas da restinga, fui espiar a peleia.

(TC) I tied the horses and, one eye on the priest and the other on the prayer book, I watched the peleia through the bushes of the sandbanks.

A palavra peleia foi grafada em itálico no texto de chegada, de modo a sinalizar que se tratava de um empréstimo, uma palavra estrangeira. Esse vocábulo é sinônimo de "briga", "contenda", "luta”.

Há casos assim no próprio texto de partida, em que o platinismo é grafado em itálico, como mostra o exemplo a seguir: 
(TP) Dentro da sala, fechada, ia um vozerio dos homens; depois serenava; parece que eles estavam mussitando; e a voz da dona repenicava, hablando un castellano de mi flor!

(TC) Inside the room, closed doors, the men talked; then it'd die down; it was like they were whisperin'; and the lady's voice rang, hablando un castellano de mi flor.

A expressão hablando un castellano de mi flor é usada para descrever um espanhol bem falado, e trata-se de um empréstimo que foi utilizado por JSLN e preservado por suas tradutoras.

Outra ocorrência de transferência pode ser observada no exemplo a seguir:

(TP) Ela só não pôde foi mudar o preceito de honra deles: brigavam, de morte, mas como guascas de lei: leais, sempre!

(TC) But one thing she couldn't change was their code of honor: they fought to the death, but as honorable guascas: loyal, always!

O regionalismo guascas tem duas conotações: a de uma tira de couro usada como correia ou rédea de cavalos e a de homem do campo, um sinônimo de "gaúcho"; no contexto do conto, a palavra se refere ao segundo sentido, e permanece inalterada no texto de chegada.

\section{Considerações finais}

A análise proposta neste trabalho não se pretendeu exaustiva, uma vez que o objetivo, aqui, foi mostrar como a tradução, especialmente quando se trata de categorias culturais, é sempre um exercício de perdas e ganhos. 0 trabalho das tradutoras é resultado de um esforço para não deixar cair no esquecimento e expandir os horizontes da obra de João Simões Lopes Neto, patrimônio da cultura sul-rio-grandense e pelotense.

As estratégias de tradução apresentadas mostram uma preocupação em tornar a leitura fluida e clara para o novo público-alvo, sem, no entanto, 
perder o colorido regionalista, através da manutenção de referências culturais como gaucho, Farrapo, guasca, peleia, entre outros, típicos do dialeto pampeano. Dos vocábulos e expressões analisados, há o emprego de diferentes estratégias, mas nunca a omissão total dos referentes culturais, tão importantes e distintivos na escrita simoneana.

É possivel expandir a análise da obra do escritor pelotense, seja recorrendo a outras traduções para a língua inglesa, seja partindo das versões para outras línguas, como as que estão presentes no belo trabalho de Fischer, Garcia e Lucena (2017). A prática tradutória e o campo dos Estudos da Tradução oferecem diversas possibilidades, e a obra desenvolvida por esses pesquisadores deixa claro que a literatura de JSLN, apesar de seu caráter fortemente regionalista, só tem a ganhar e a acrescentar ao ser dividida com o resto do mundo.

\section{Referências}

AIXELÁ, J. F. Culture-specific items in Translation. In: AVARRÉZ, R.; VIDAL, M. C. A. (ed.). Translation, power and subversion. Clevedon: Multilingual Matters, 1996. p. 52-78.

BAKER, M. In Other Words: A Coursebook on Translation. 3a. ed. London; New York: Routledge, 2018.

Chesterman, A. Memes of Translation. 2a. ed. Amsterdam; Philadelphia: John Benjamins, 2016.

FAÉ, G. Regionalidade em Simões Lopes Neto: fortuna crítica. Revista Eletrônica de Estudos Literários, Vitória, v. 2, n. 8, p. 1-18, 2011.

FISCHER, L. A.; GARCIA, R. N.; LUCENA, K. de C. Simões Lopes Neto para o Mundo. Porto Alegre: Editora UFRGS, 2017.

HendRICKSON, R. The Facts on File Dictionary of American Regionalisms. New York: Facts on File, 2000.

Newmark, P. A Textbook of Translation. New York: Prentice Hall International, 1988.

Pozenato, J. C. Processos culturais: reflexões sobre a dinâmica cultural. Caxias do Sul: EDUCS, 2003. 
SCHLEE, A. G. Lembrança de João Simões Lopes Neto. Pelotas: Fructo do Paiz, 2010.

SCHLEE, A. G. Vocabulário de João Simões Lopes Neto. Pelotas: Fructo do Paiz, 2009.

Recebido em: 31/01/2019

Aceito em: 02/05/2019

Publicado em maio de 2019 